\title{
Simplified Interception/Evaporation Model
}

\author{
Giorgio Baiamonte (1)
}

check for

updates

Citation: Baiamonte, G. Simplified Interception/Evaporation Model. Hydrology 2021, 8, 99. https:// doi.org/10.3390/hydrology8030099

Academic Editors: Aristoteles Tegos and Nikolaos Malamos

Received: 6 June 2021

Accepted: 30 June 2021

Published: 2 July 2021

Publisher's Note: MDPI stays neutral with regard to jurisdictional claims in published maps and institutional affiliations.

Copyright: (C) 2021 by the author. Licensee MDPI, Basel, Switzerland. This article is an open access article distributed under the terms and conditions of the Creative Commons Attribution (CC BY) license (https:/ / creativecommons.org/licenses/by/ $4.0 /)$.
Department of Agricultural, Food and Forest Sciences (SAAF), University of Palermo, Viale delle Scienze, 90128 Palermo, Italy; giorgio.baiamonte@unipa.it

\begin{abstract}
It is known that at the event scale, evaporation losses of rainfall intercepted by canopy are a few millimeters, which is often not much in comparison to other stocks in the water balance. Nevertheless, at yearly scale, the number of times that the canopy is filled by rainfall and then depleted can be so large that the interception flux may become an important fraction of rainfall. Many accurate interception models and models that describe evaporation by wet canopy have been proposed. However, they often require parameters that are difficult to obtain, especially for large-scale applications. In this paper, a simplified interception/evaporation model is proposed, which considers a modified Merrian model to compute interception during wet spells, and a simple power-law equation to model evaporation by wet canopy during dry spells. Thus, the model can be applied for continuous simulation, according to the sub hourly rainfall data that is appropriate to study both processes. It is shown that the Merrian model can be derived according to a simple linear storage model, also accounting for the antecedent intercepted stored volume, which is useful to consider for the suggested simplified approach. For faba bean cover crop, an application of the suggested procedure, providing reasonable results, is performed and discussed.
\end{abstract}

Keywords: interception; linear storage model; evaporation; cover crop; water balance; faba bean

\section{Introduction}

According to Brutsaert [1], the interception process is determined by the rainfall fraction that moistens vegetation and that is temporarily stored on it, before evaporating. When the vegetation cover is fully saturated, the interception storage capacity is achieved. In practice, the interception storage capacity is denoted as rainfall left on the canopy at the end of the rainfall after all drip has ceased [2]. The water stored on the canopy may evaporate soon after, thus short-circuiting the hydrologic cycle.

Although most surfaces can store only a few millimeters of rainfall, which is often not much in comparison to other stocks in the water balance, interception is generally a significant process and its impact becomes evident at longer time scales [3]. Thus, interception storage is generally small, but the number of times that the storage is filled and depleted can be so large that the evaporation losses by wet canopy may become of the same order of magnitude as the transpiration flux [4].

Evaporation flux by canopy exerts a negative effect on plant water consumption by preventing water from reaching the soil surface, thus the plant roots [2,3]. In contrast, the remaining rainfall (i.e., the net rainfall) reaches the soil surface either as throughfall or by flowing down branches and stems as stemflow. Throughfall is the fraction of water that reaches the soil surface directly through the canopy gaps without hitting the canopy surfaces, or indirectly through dripping from the leaves and branches [5].

The interception may also exert important effects on surface runoff [6], providing a certain delay compared with the time of the beginning of the rain. For the Dunnian mechanism of runoff generation, Baiamonte [7] showed the effect induced by the interception process on the delay time, and emphasized that the effect is more frequent for well-drained soils [8,9] in humid regions, for low rainfall intensities and high groundwater table, when infiltration capacity exceeds the rainfall intensity. Indeed, the latter conditions also occurs 
for high density of cover crops or forest soils that are reach in organic carbon and are very structured [10].

The proportion of the precipitation that does not reach the ground, i.e., the interception loss, depends on the type of vegetation (forest, tree, or grassland), its age, density of planting and the season of the year. The interception loss also depends on rainfall regime, thus on climate. For example, in tall dense forest vegetation at temperate latitudes interception loss as large as 30-40\% of the gross precipitation has been observed [11], whereas in tropical forest with high rainfall intensity was of the order 10-15\% [12] and in heather and shrub also $10-15 \%$ [13]. In arid and semi-arid areas, where there is little vegetation, the interception loss is negligible.

Since interception is an important component of the water balance, a comprehensive evaluation of interception loss by prediction tools has been considered of great value in the study of hydrological processes, and different formulations, at hourly and event scale, have been introduced in the hydrologic literature. Muzylo et al. [14] wrote an interesting review paper, where the principal models proposed in the literature are described, and their characteristics reported (input temporal scale, output variable, number of parameters, layers, spatial scale).

Linsley et al. [15] modified the very simple interception model first introduced by Horton [16], which did not account for the amount of gross rainfall, since it assumed that the rainfall in each storm completely filled the interception storage. Linsley et al. [15] assumed that the interception loss approached exponentially to the interception capacity as the amount of rainfall increased [17]. Then, this simple sketch was applied and tested by Merrian [18], who studied the effect of fog intensity and leaf shape on water storage on leaves, by using a simple fog wind tunnel and leaves of aluminum and plastic. Merrian [18] found that drip measurements were reasonably close to values predicted, by using an exponential equation based on fog flow and leaf storage capacity.

Rutter et al. $[19,20]$ were the first to model forest rainfall interception recognizing that the process was primarily driven by evaporation from the wetted canopy. The conceptual model developed by Rutter et al. $[19,20]$ describes the interception loss in terms of both the structure of the forest and the climate in which it is growing. The model is physically based, thus it has potential for application in all areas, where there are suitable data. In Rutter et al. [20], the model's definitive version was developed by adding a stemflow module, in which a fraction of the rainfall input is diverted to a compartment comprising the trunks. Early applications of Rutter-type models were made by Calder [21] and Gash and Morton [22].

The rate of evaporation increases with solar radiation and temperature. The process also depends on the air humidity and the wind speed. The greater the humidity, the less the evaporation. Wind carries moist air away from the ground surface, so wind decreases the local humidity and allows more water to evaporate. Therefore, in the Rutter model, the evaporation flux was calculated from the form of the Monteith-Penman equation [23]. Later, Gash [24] provided a simplification of the data-demanding Rutter model. Although some of the assumptions of the Gash model may not be suitable, the model has been shown to work well under a variety of forest types, including different species and sites [11,25-27].

For agricultural crops and for grassland, where interception loss is of the order 13-19\% [28], Von Hoyningen-Hüne [29] and Braden [30], proposed a general formula, which was used in the SWAP model [31] that however can be applied only at daily scale.

By the experimental point of view, the interception evaporation process requires monitoring intercepted mass and interception loss with high accuracy and time resolution, to provide accurate estimates. Net precipitation techniques, in which interception evaporation is determined from the difference between gross precipitation and throughfall, fulfill many of the requirements but usually have too-low accuracy and time resolution for process studies. Furthermore, for grassland, these techniques are unsuitable.

In this paper, we explored the rainfall partitioning in net rainfall and evaporation losses by canopy, by using a very simplified sketch of the interception process, which 
combines a modified exponential equation applied and tested by Merrian [18], accounting for the antecedent volume stored on the canopy, and a simple power-law equation to compute evaporation by wet canopy. We are aware that the considered approach is far from the sophisticated physically based developments that were performed to quantify interception and evaporations losses. However, the latter may require many parameters that are not easy to determine. It is shown that the simplified parsimonious approach may lead to a reasonable quantification of this important component of the hydrologic cycle, which can be useful when a rough estimate is required, in absence of a detailed characterization of the canopy and of the climate conditions. It is also shown that the Merrian model can be derived by considering a simple linear storage model. For faba bean cover crop, an application of the suggested procedure is performed and discussed.

\section{Rainfall Data Set, Wet and Dry Spells}

Rainfall time series were analyzed according to Agnese et al. [32], who applied the discrete three-parameter Lerch distribution to model the frequency distribution of interarrival times, $I T$, derived from daily precipitation time-series, for the Sicily region, in Italy. Agnese et al. [32] showed a good fitting of the Lerch distribution, thus evidencing the wide applicability of this kind of distribution [33], also allowing us to jointly model dry spells, $D S$, and wet spells, WS.

Since this work aimed at modelling by continuous rainfall data series the interception losses, during the WS and the evaporation losses during $D S$, only the frequency distribution of the two latter were considered, which are defined in the following, according to Agnese et al. [32].

For any rainfall data series, the ten minutes temporal scale, $\tau$, which is appropriate to model both interception and evaporation processes, could be considered in order to describe clustering and intermittency characters of continuous rainfall data series.

Let $H=\left\{h_{1}, h_{2}, \ldots, h_{n}\right\}$, a time-series of rainfall data of size $n$, spaced at uniform time-scale $\tau$. The sub-series of $H$ can be defined as the event series, $E\left\{t_{1}, t_{2}, \ldots, t_{n E}\right\}$, where $n_{E}\left(0<n_{E}<n\right)$ is the size of $E$, which is an integer multiple of time-scale $\tau$. The succession constituted by the times elapsed between each element of the $E$ series, with exception of the first one and the immediately preceding one, is defined as the inter-arrival time-series, IT $\left\{T_{1}, T_{2}, \ldots, T_{n E}\right\}$, with size $n_{E-1}$ (Figure 1 ). It can be observed the sequence of dry spells, $D S$, can be derived from $I T$ dataset by using the relationship $\left\{D S_{k}\right\}=\left\{T_{k}\right\}-1$ for any $T_{k}>1$.

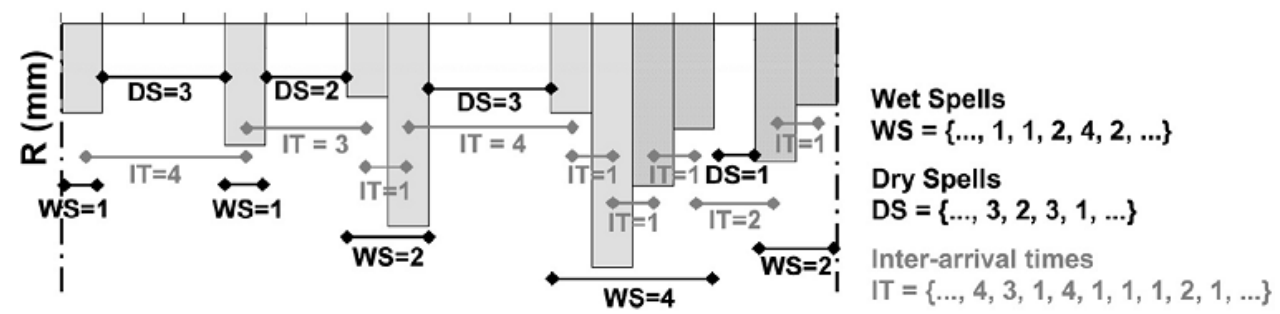

Figure 1. Sketch of inter-arrival times (IT), dry spells (DS) and wet spells (WS). Reprinted with permission from ref. [32], Copyright 2014, Elsevier (Amsterdam, The Netherlands).

Figure 1 shows an example of a sequence of wet and dry spells. In the context of this work, which aims at modelling the interception process during WS and the evaporation process from the canopy, as previously observed, only the frequency distribution of wet spells (WS) and dry spells (DS) were derived.

For the 2009 rainfall data series of Fontanasalsa station (Trapani, $37^{\circ} 56^{\prime} 37^{\prime \prime} \mathrm{N}, 12^{\circ} 33^{\prime} 12^{\prime \prime} \mathrm{E}$, western Sicily, Italy), which will be considered for an example application, Figure 2 shows the complete characteristics of the rainfall regime. In particular, Figure 2a describes the $D S$ distribution of frequency, $F$, whereas Figure $2 \mathrm{~b}$ plots the WS distribution associated with the cumulated rainfall depth collected with $10 \mathrm{~min}$ time resolution. Both figures also illustrate the frequency of non-exceedance, corresponding the selected time resolution $(\tau=1=10 \mathrm{~min})$ 
that equals 0.189 for DS and much higher for WS (0.596), indicating that a high fraction of rainfall with WS $=1$ occurs, which could play an important role in the interception process. Figure $2 \mathrm{~b}$ also plots the rainfall depth distribution corresponding to $W S$, where the frequency is calculated with respect to the yearly rainfall depth, $h_{\text {year }}$, which equals $885.2 \mathrm{~mm}$. Therefore, in Figure $2 \mathrm{~b}$, to $W S=1\left(F_{1}=0.115\right)$ corresponds a rainfall depth equals to $101.6 \mathrm{~mm}$ that, if associated with subsequent large enough $D S$, may potentially evaporate from the canopy.
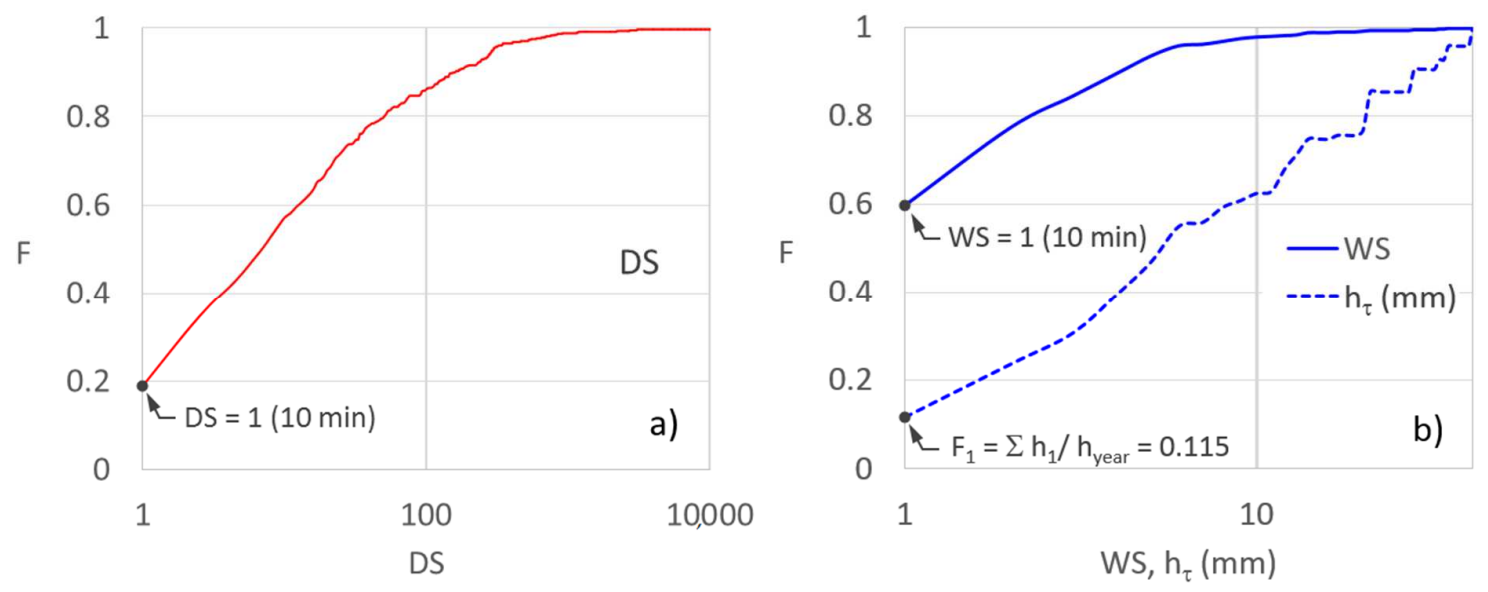

Figure 2. For the investigated year (2009), distributions of frequency, $F,(\mathbf{a})$ of dry spells (DS), and (b) of wet spells (WS) and of the rainfall depth $\left(h_{\tau}\right)$ corresponding to WS.

\section{Interception Rate and Stored Volumes during Wet Spells}

The interception Merrian [18]'s model states that:

$$
I C S=S\left[1-\exp \left(-\frac{R}{S}\right)\right]
$$

where $S(\mathrm{~mm})$ is the interception capacity of the canopy, and ICS $(\mathrm{mm})$ is the interception storage volume corresponding to the cumulated rainfall volume $R(\mathrm{~mm})$. Equation (1) can be applied for dry initial condition, i.e., when the no water volume is stored on the canopy at the beginning of the rainfall.

However, it is demonstrated here that the Merrian model can be derived by considering a simple linear stored model, also used in other hydrological contexts [34], which made it possible to also account for the antecedent interception volume. The latter is useful for the applications, when in between two consecutive WSs, DS is not long enough to result in full evaporation of the rainfall volume intercepted by the canopy starting from the end of a WS. Thus, a residual water volume, ICS $S_{0}$, is still stored on the canopy at the beginning of the subsequent WS, and it needs to be considered as initial condition. Therefore, for the purpose of this study, which aims at estimating interception losses during WS and DS sequences of different amount and duration, Equation (1) needs to be extended to different antecedent water interception storage volume, $I C S_{0}(\mathrm{~mm})$, before a new WS takes place, after a $D S$ when evaporation process ceases.

Consider a simple linear reservoir, miming the interception storage volume (Figure 3). A stationary rainfall of intensity $r\left(\mathrm{~mm} \mathrm{~h}^{-1}\right)$ uniformly distributed over the canopy, is applied to the reservoir. In the time $d t$, the interception storage, ICS ( $\mathrm{mm}$ ), stored in the canopy equals $d I C S$. The interception capacity, i.e., the maximum rainfall volume that can be stored on the canopy, is denoted as $S(\mathrm{~mm})$. The duration of rainfall that needs to achieve the saturation of the canopy, without dripping out from the reservoir, $t_{s}(\mathrm{~h})$, can be expressed as:

$$
t_{s}=\frac{S}{r}
$$




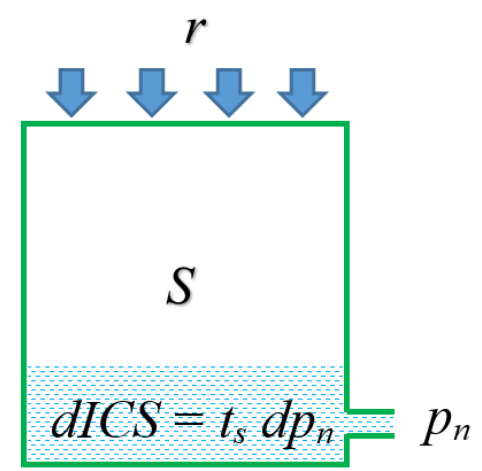

Figure 3. Sketch of the linear water tank describing the interception process, for a maximum water volume stored on the canopy, $S(\mathrm{~mm})$, corresponding to the interception capacity.

From a physical point of view, $t_{s}$ is not very meaningful since it describes the duration of rainfall that is required for the canopy saturation, for dry antecedent conditions $\left(I C S_{0}=0\right)$, and with no losses from the reservoir, e.g., no dripping and no net rainfall intensity $p_{n}\left(\mathrm{~mm} \mathrm{~h}^{-1}\right)$, which actually occurs (Figure 3$)$. However, $t_{s}$ represents a characteristic time of the interception process that it is useful to introduce for the following derivations.

By assuming that the water volume stored in the reservoir linearly varies with the output net rainfall intensity, $p_{n}$, according to the time $t_{s}$ (Equation (2)), the balance of the water volumes can be expressed as:

$$
r d t-p_{n} d t=d I C S=t_{s} d p_{n}
$$

Separation of variables may be used to solve the ordinary differential equation:

$$
d t=\frac{t_{s}}{r-p_{n}} d p_{n}
$$

By assuming as initial conditions:

$$
t=t_{0} \quad p_{n}=p_{n 0}
$$

Integration of Equation (4) provides:

$$
\int_{t_{0}}^{t} d t=\int_{p_{n 0}}^{p_{n}} \frac{t_{s}}{r-p_{n}} d p_{n}
$$

Solving Equation (6) yields:

$$
t=t_{0}+t_{s} \log \frac{r-p_{n 0}}{r-p_{n}}
$$

Equation (7) can be made explicit to derive the net rainfall intensity, $p_{n}$ :

$$
p_{n}=r-\left(r-p_{n 0}\right) \exp \left(-\frac{t-t_{0}}{t_{s}}\right)
$$

Of course, knowledge of Equation (8) makes it possible to determine the interception intensity, ics $(\mathrm{mm} / \mathrm{h})$ :

$$
i c s=r-p_{n}=\left(r-p_{n 0}\right) \exp \left(-\frac{t-t_{0}}{t_{s}}\right)
$$


Due to the assumption of a linear storage model, the antecedent net rainfall intensity, $p_{n 0}$, in Equations (8) and (9), is linked to the antecedent interception volume, ICS $S_{0}$, by:

$$
p_{n 0}=\frac{I C S_{0}}{t_{s}}=r \frac{I C S_{0}}{S}
$$

For a compacted graphical illustration, a constant rainfall intensity, $r$, and a zero time antecedent condition $t_{0}=0$ can be assumed. Thus, Equations (8) and (9) normalized with respect to $r$ can be expressed as:

$$
\begin{gathered}
\frac{p_{n}}{r}=1-\left(1-\frac{I C S_{0}}{S}\right) \exp \left(-\frac{R}{S}\right) \\
\frac{i C S}{r}=\left(1-\frac{I C S_{0}}{S}\right) \exp \left(-\frac{R}{S}\right)
\end{gathered}
$$

where in Equations (8) and (9) $t_{s}$ was substituted by Equation (2), and $r$ by $R t$, with $R$ $(\mathrm{mm})$ the cumulated rainfall depth. Equations (11) and (12) are graphed in Figure $4 a, b$, respectively. For any fixed $S$, and for a fixed antecedent interception storage volume, ICS Figure 4a shows that, at increasing $R$, the net rainfall intensity, $p_{n}$, attains the gross rainfall intensity $r\left(p_{n} / r \sim 1\right)$, and that, at increasing ICS $S_{0}$, the $r$ achievement is slower and slower, as it could be expected. Of course, the normalized interception intensity $i c s / r$ plotted in Figure $4 \mathrm{~b}$ provides complementary curves.
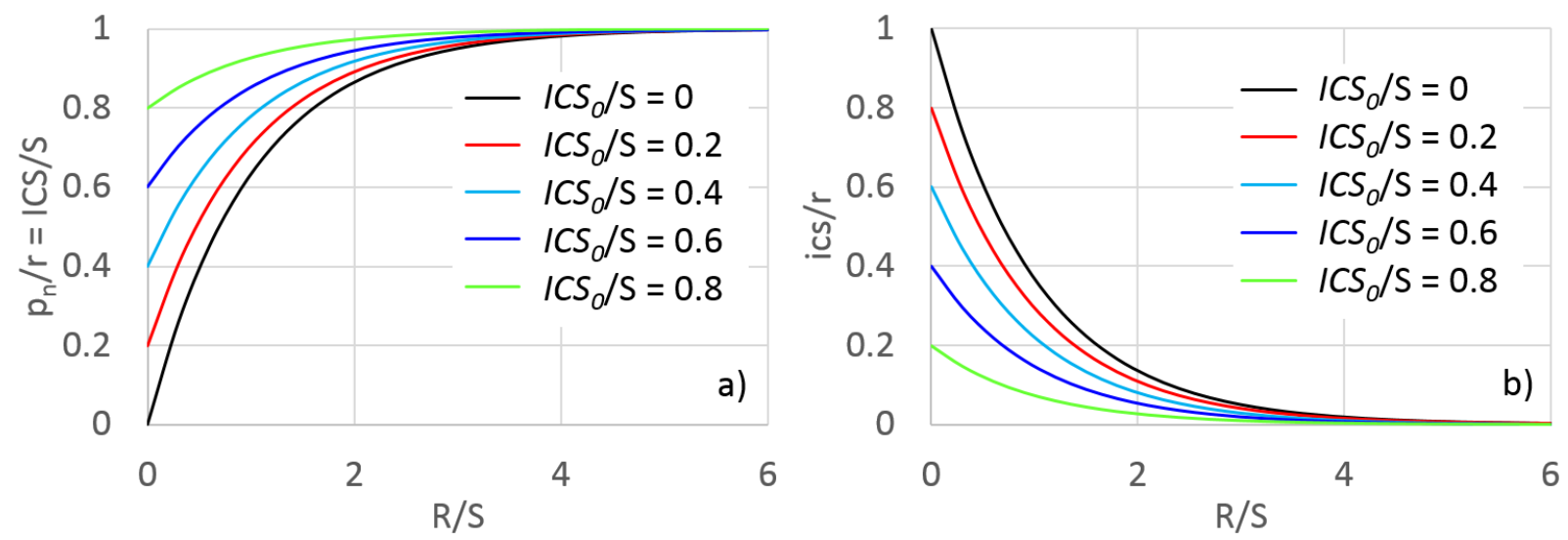

Figure 4. For different antecedent normalized water volume stored on the canopy, $I C S_{0} / S$, (a) normalized interception volume, ICS $/ S$, corresponding the normalized net rainfall intensity, $p_{n} / r$, and (b) normalized interception intensity, ics $/ r$, versus the normalized rainfall volume, $R / S$.

In order to determine the interception volume, ICS $(\mathrm{mm})$, as a function of its antecedent amount, $I C S_{0}(\mathrm{~mm})$, because of the assumption of a linear storage model (Equation (10)), it can be easily observed that Equation (11) also matches the interception storage volume, ICS, normalized with respect to the infiltration capacity, $S$ :

$$
\frac{I C S}{S}=1-\left(1-\frac{I C S_{0}}{S}\right) \exp \left(-\frac{R}{S}\right)
$$

as displayed in the vertical axis label of Figure 4a. Therefore, Equation (13) is formally equivalent to Equation (11), but with a different meaning of the output parameters.

It is noteworthy to observe that, for dry antecedent condition $\left(I C S_{0}=0\right)$, Equation (13) matches the interception storage model (Equation (1)) proposed by Merrian [18], which was developed only for dry initial conditions, as previously observed.

Equation (13) could also be derived analytically, with a lesser extend from a physical point of view, than that provided by the simple linear stored model previously described. 
Indeed, denoting $R_{0}$ the antecedent rainfall volume corresponding to $I C S_{0}$, the Merrian's model (Equation (1)) yields:

$$
I C S=S\left[1-\exp \left(-\frac{R}{S}-\frac{R_{0}}{S}\right)\right]
$$

The antecedent rainfall volume, $R_{0}$, can be expressed as a function of $I C S_{0}$ by using Equation (1):

$$
R_{0}=-S \log \left(1-\frac{I C S_{0}}{S}\right)
$$

Substituting Equation (15) into Equation (14), and normalizing ICS with respect to $S$, provides Equation (13), which was to be demonstrated.

As an example, for $S=0.5 \mathrm{~mm}$ and $I C S_{0}=0$, and for a constant rainfall intensity $r=1.75 \mathrm{~mm} / \mathrm{h}$, Figure 5 graphs ICS vs. the cumulated rainfall $R$ (solid black line). For $R_{0}=0.7 \mathrm{~mm}$, corresponding to $I C S_{0}=0.377 \mathrm{~mm}$, Equation (14) is plotted in Figure 5 (red line), which of course is not physical meaningful for $R<0$ (dashed line).

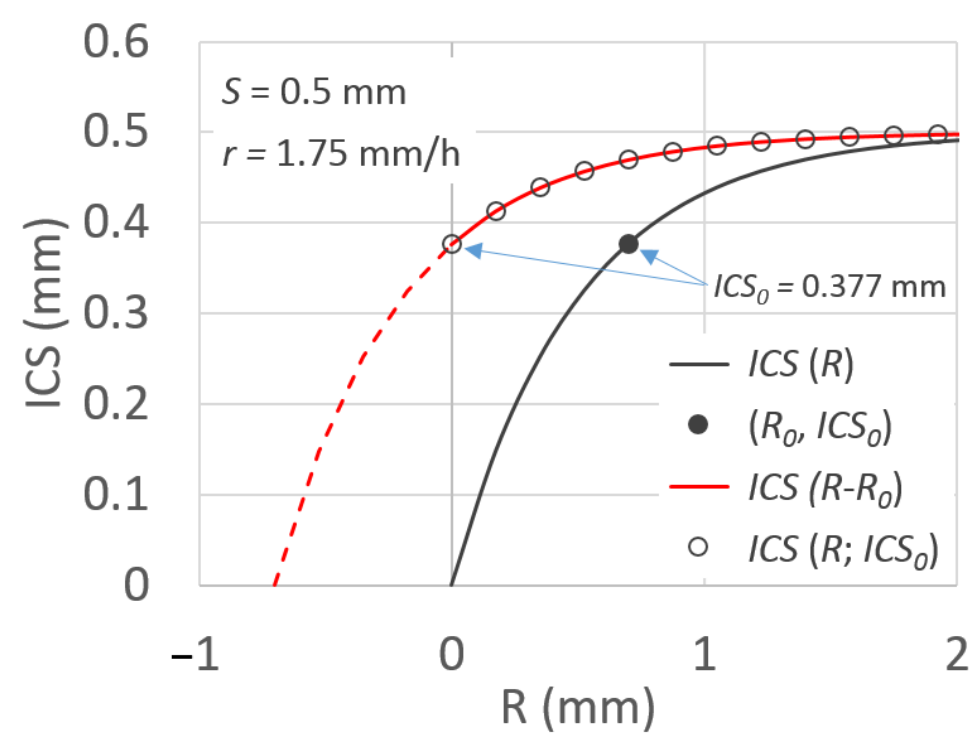

Figure 5. Relationship between the interception storage, ICS ( $\mathrm{mm})$, and the rainfall depth, $R(\mathrm{~mm})$, for dry antecedent condition, $I C S_{0}=0$, according to Merrian [18], and for a wet antecedent condition $\left(I C S_{0}=0.377 \mathrm{~mm}\right)$.

For $I C S_{0}=0.377 \mathrm{~mm}$, Equation (13) is also plotted in Figure 5 (round circles) showing that Equation (13) matches Equation (14). Equation (13) will be used in the following to calculate the interception storage volume starting from any $I C S_{0}$ value.

\section{Evaporation by Wet Canopy during Dry Spells}

During a dry spell, DS, starting from an antecedent storage volume, $I C S_{0}>0$, the evaporation process from the wet canopy takes place. When the canopy is wetted by rain, evaporation of intercepted rainfall is largely a physical process that does not depend on the functioning of stomata. According to a realistic description of evaporation from canopies the Penman-Monteith equation $[23,35]$ could be used, by imposing zero the surface (or canopy) resistance.

However, a different approach is used here, which is based on the physical circumstance highlighted well by Babu et al. [36] that evaporation by wet canopy comprises two stages. First, the drying process involves removal of unbound (free) moisture from the surface, and second it involves removal bound moisture from the interior of the leaf till a defined limit, corresponding to a critical moisture content. Apart from the second stage, which refers to water consumption by the canopy, and thus it is beyond the purpose of this study, the first 
stage comprises (i) a "preheat period", where the drying speed quickly increases, and then (ii) a "constant rate period", where evaporation takes place at the outside surface for the removal of unbound moisture (free water) from the surface of the leaf [36].

The evaporation mechanism by wet canopy of the first stage could be also described by the physical equations requiring the knowledge of climatic parameters and structure parameters of the canopy. However, in agreement with the simple sketch also considered for the interception process, in this simplified study the first stage evaporation mechanism is described by a simple power-law, according to two parameters. A similar power-law equation was also considered by Black et al. [37] to model the cumulative evaporation of an initially wet, deep soil. For the same power-law equation, Ritchie [38] reports the experimental parameters obtained by other researchers for different soils.

One limited experimental campaign, described in the next section for the faba bean, supported this choice and revealed that for fixed outdoor air temperature, $T_{e x}\left({ }^{\circ} \mathrm{C}\right)$ the cumulated evaporation volume, per unit leaf surface area, $E(\mathrm{~mm})$, could be actually described by the power-law equation:

$$
E=m t^{n} \text { for a fixed } T_{e x}\left({ }^{\circ} \mathrm{C}\right)
$$

where $t(\mathrm{~h})$ is the time spent after the canopy interception capacity, $S$, is achieved, $m$ is a scale parameter and $n$ a shape parameter to be determined by experimental measurements.

In order to upscale Equation (16) to any values of air temperature, a regional equation developed for the Sicily region was considered [39]:

$$
E_{m}=0.38 T_{m}^{1.93}
$$

where $E_{m}(\mathrm{~mm})$ is the monthly evaporation depth and $T_{m}\left({ }^{\circ} \mathrm{C}\right)$ is the monthly temperature. By scaling Equation (16) with Equation (17), provides:

$$
E=\operatorname{LAI} m t^{n}\left(\frac{T_{m}}{T_{e x}}\right)^{1.93}
$$

where the leaf area index, $L A I$, was introduced, accounting for the actual leaf surface from which the water evaporates. Of course, Equation (18) gives the same experimental evaporation amount derived by Equation (17), when the experimental air temperature, $T_{e x}$, is equal to $T_{m}$.

It should be noted that Equation (18) does not account for wind speed, thus evaporation losses are linked to the wind experimental conditions for which $m$ and $n$ parameters are determined, otherwise losses are underestimated or overestimated for wind speeds lower and higher than the experimental ones, respectively. Moreover, application of this procedure in regions different from Sicily would require modifying Equations (17) and (18).

For $L A I=2$ and $T_{e x}=18{ }^{\circ} \mathrm{C}$, and for fixed experimental values of $m$ and $n$ parameters, Figure 6 shows evaporation losses, $E$, during the time, with the air temperature, $T_{m}$, as a parameter.

In order to apply the suggested procedure, according to the discrete nature of rainfall, the cumulated evaporation volume (Equation (18)) needs to be expressed in discrete terms by accounting, as per the interception model, for the antecedent conditions, at the aim to determine the $E$ fraction, $\Delta E$, which occurs during the dry spells, $D S$, starting from $t_{0}$ :

$$
\Delta E=\operatorname{LAIm}\left(\frac{T_{m}}{T_{e x}}\right)^{1.93}\left(\left(D S+t_{0}\right)^{n}-t_{0}^{n}\right)
$$

where the antecedent initial condition, $t_{0}$, refers to the end of the wet spell, WS, when the evaporation process starts. Thus, $t_{0}$ needs to be calculated by Equation (19), by assuming 
that the evaporation initial condition, $E_{0}$, equals the interception capacity minus the water stored in the canopy as interception, $S-I C S$ :

$$
t_{0}=\left(\left(\frac{T_{e x}}{T_{m}}\right)^{1.93} \frac{S-I C S}{L A I m}\right)^{1 / n}
$$

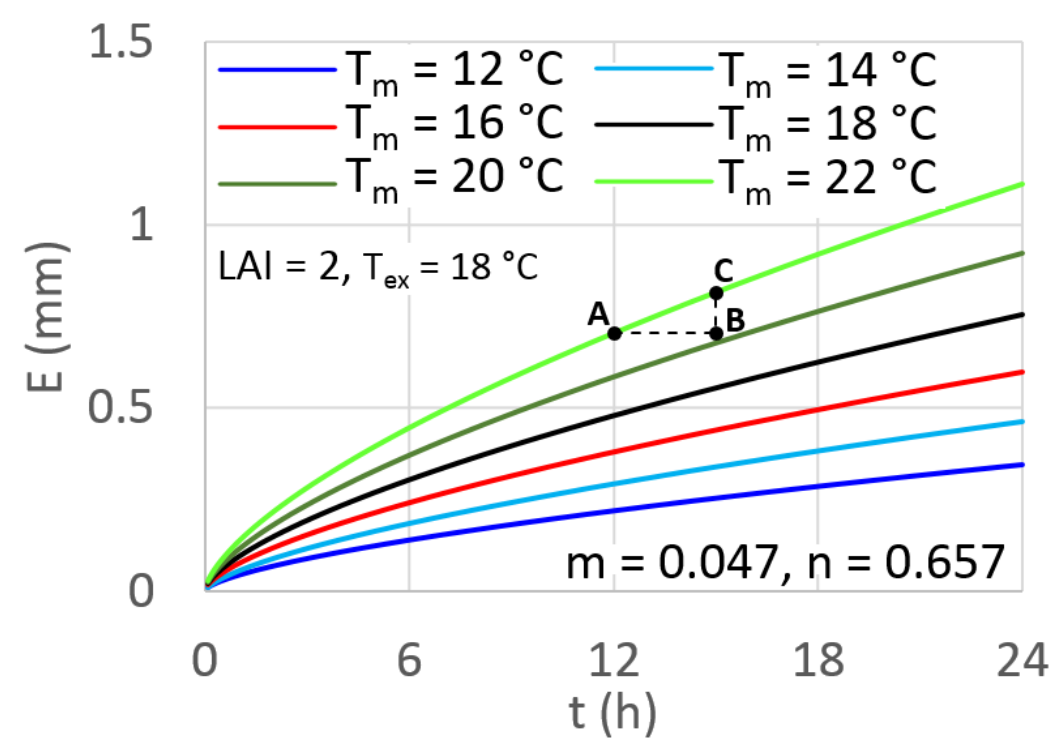

Figure 6. For $L A I=2$ and an experimental temperature, $T_{e x}=18^{\circ} \mathrm{C}$, evaporation losses by canopy per unit surface leaf, $E(\mathrm{~mm})$, during the time $t(\mathrm{~h})$, starting from the interception capacity $(E=0$, $t=0$ ), with air temperature, $T_{m}\left({ }^{\circ} \mathrm{C}\right)$, as a parameter. For $T_{m}=22{ }^{\circ} \mathrm{C}$ and $D S=3 \mathrm{~h}$, the figure also illustrates the evaporation loss, $\Delta E(\mathrm{~mm})$, corresponding to the segment $\mathrm{B}-\mathrm{C}$, starting from an initial condition $\mathrm{A}=\left(t_{0}, E_{0}\right)$ drier than saturation.

By using Equations (18) and (20), an example of $\Delta E$ calculation (Equation (19)), which is useful for the applications that will be shown, is performed here. Let assume $m=0.047$, $n=0.657, T_{e x}=22{ }^{\circ} \mathrm{C}$ (Figure 6), and an evaporation loss $\Delta E$ for a mean temperature of $T_{m}=22{ }^{\circ} \mathrm{C}$ needs to be determined. The interception capacity $S$ equals $1.5 \mathrm{~mm}$, and the interception volume stored in the canopy ICS when the evaporation process takes place equals $0.8 \mathrm{~mm}$, thus the difference $S-I C S=0.7 \mathrm{~mm}$ mimics the amount water loss due to a virtual evaporation till $E_{0}$ (Figure 6). The corresponding initial condition $t_{0}$, calculated by Equation (20) provides $12 \mathrm{~h}$. The pair $\left(t_{0}, E_{0}\right)$ is illustrated in Figure 6 (point A).

Assuming that $\Delta E$ needs to be calculated after a $D S=3 \mathrm{~h}$, Equation (19) yields $\Delta E=0.111 \mathrm{~mm}$, which corresponds to the segment B-C in Figure 6, also indicating an evaporation loss $E=E_{0}+\Delta E=0.816 \mathrm{~mm}$ (point $C$ ).

In order to consider that $\Delta E$ computation is limited by the antecedent volume stored water on the canopy, ICS, actually available to evaporate, the following condition was imposed, and a corrected $\Delta E$, denoted as $\Delta E_{*}$ evaluated:

$$
\begin{gathered}
\Delta E_{*}=I C S \quad \text { if } \Delta E>I C S \\
\Delta E_{*}=\Delta E \quad \text { otherwise }
\end{gathered}
$$

In both interception and evaporation models previously introduced, neither the canopy actually covering the field (cover fraction), nor the proportion of rain which falls through the canopy without striking a surface (throughfall), were taken into account. In the next section, the latter issues are considered and then the water mass balance is analyzed. 


\section{Water Mass Balance}

The fraction of ground covered by the canopy [40] plays a fundamental role in estimating interception losses, as well as the proportion of rain that falls through the canopy without striking any surface. In the following, in order to analyze the water mass balance, $C_{F}$ denotes the fraction of ground covered by the canopy and $p$ is the free throughfall coefficient $[19,20]$. Assuming $p=0$, meaning that the canopy fully covers the ground at the plant scale, Figure 7 shows two very different conditions in terms of $L A I$ and $C_{F}$, which could provide similar evaporation losses, since high $C_{F}$ (Figure 7a) could be counterbalanced by low LAI (Figure 7b), and vice versa.

a)

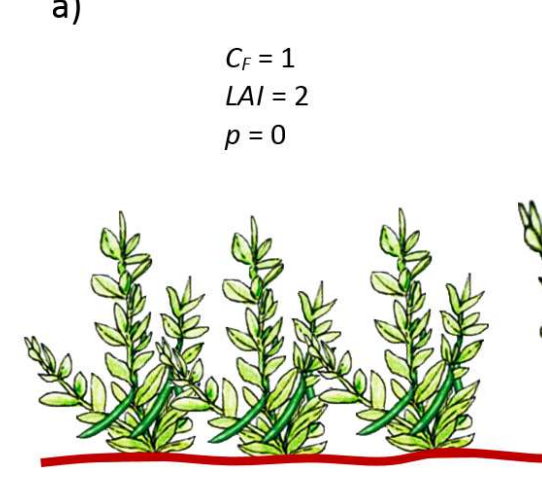

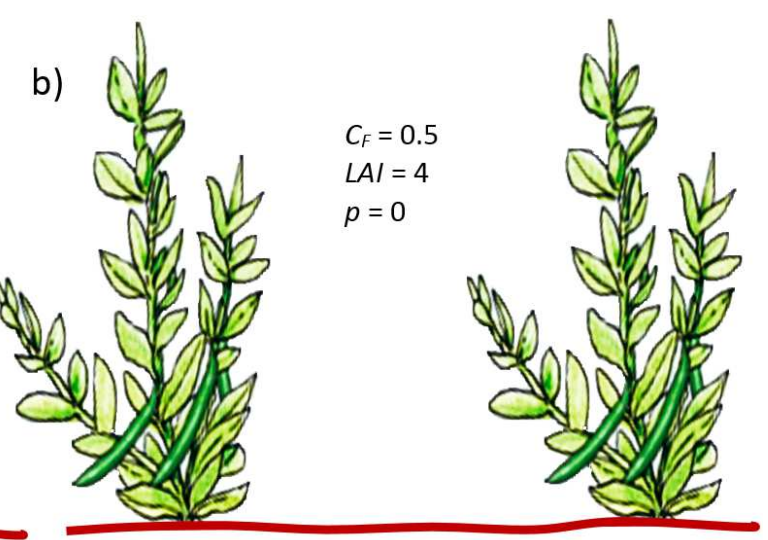

Figure 7. For faba bean, two different attributions of the parameters $L A I$, throughfall index, $p$, and fraction of ground covered by the canopy, $C_{F}$.

By considering both $C_{F}$ and $p$, as weighting factors, for a gross rainfall depth $R(\mathrm{~mm})$, the water mass balance is described by the following relationship:

$$
R=R_{f}+R_{c}+R_{t}=R\left(1-C_{F}\right)+R C_{F}(1-p)+R C_{F} p
$$

where $R_{f}(\mathrm{~mm})$ is the portion of $R$ that freely achieves the ground in between the plants, $R_{c}$ $(\mathrm{mm})$ is the fraction of $R$ that achieves the canopy, and $R_{t}(\mathrm{~mm})$ is the throughfall.

Thus, depending on the plant species, both $p$ and $C_{F}$ affect $R_{c}$ and could be simply determined by using RGB images [41,42]. According to Equation (22), to evaluate interception losses, in Equation (13) $R$ has to be replaced by $R_{c}$.

By assuming $C_{F}=1$ and $p=0\left(R=R_{c}\right)$, for dry initial condition, $I C S_{0}=0$, for fixed parameters $S=0.8 \mathrm{~mm}, L A I=4, m=0.047, n=0.657, T_{e x}=12{ }^{\circ} \mathrm{C}$, and for three sequences of WS and DS, a simple application of the procedure is illustrated in Figure 8, where the denoted variables are also indicated. For simplicity, in the figure linear ICS and $\Delta E$ variations were assumed.

Figure 8 shows that for the third $D S$ a high air temperature $\left(T_{m}=20^{\circ} \mathrm{C}\right)$ provides the condition $\triangle E>I C S$, and only the available water stored on the canopy may evaporate $\left(\Delta E_{*}\right)$. Moreover, for this step, according to the initial condition $\left(t_{0}, E_{0}\right)$, the evaporation flux (i.e., the slope) is higher than those corresponding to the lower air temperatures.

For fixed $T_{m}=12{ }^{\circ} \mathrm{C}$, the evaporation flux is greater for the second $D S$ step that starts from a higher $I C S_{0}$, which is near to the saturation compared to that of the first $D S$ step. Similarly, for the second WS step, although the higher rainfall depth $(R=2 \mathrm{~mm})$ with respect to the first WS step, ICS increases as in the first WS step, because of a higher initial condition $I C S_{0}$, agreeing with the dynamic flux of the both considered interception/evaporation models. 


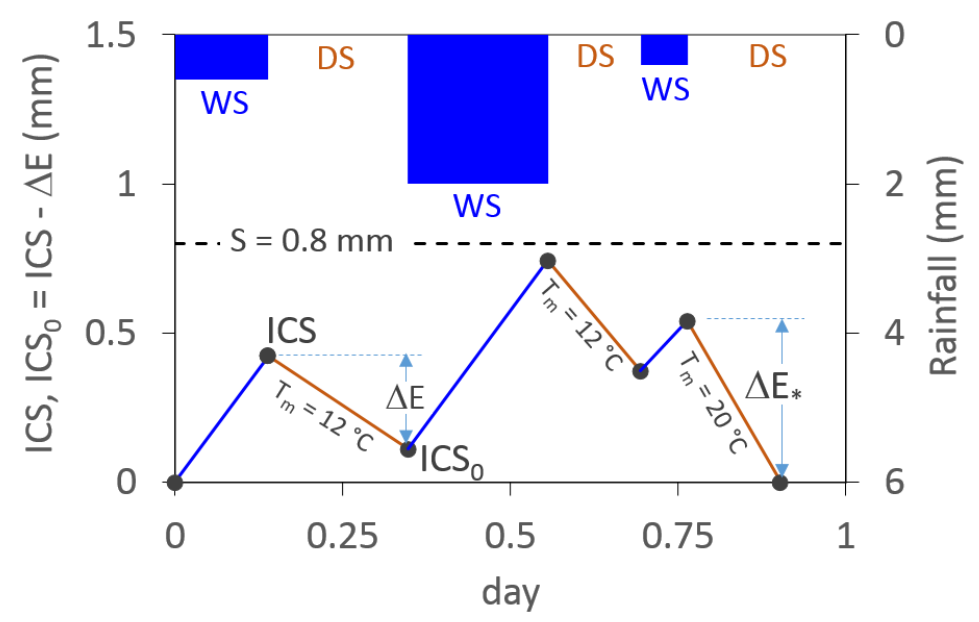

Figure 8. For a simple sequence of three WSs and DSs, interception loss during WS, and evaporation loss, $\Delta E$, during $D S$, with $E_{0}=S-I C S$ as initial condition. For the third $D S$, the condition described by Equation (21) occurs $(\Delta E>I C S)$ and $\Delta E_{*}=I C S$.

The flow chart displayed in Figure 9 describes the suggested procedure to calculate the interception/evaporation water losses, which will be used in the following application, where the condition to be imposed (Equation (21)) is also indicated.

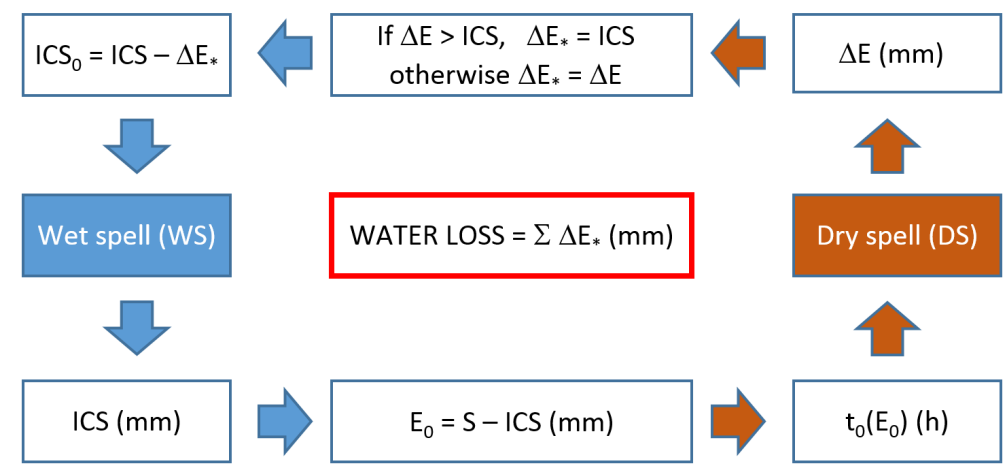

Figure 9. Schematic flowchart of the proposed methodology to calculate ICS during WS, and $\triangle E$ (or $\left.\Delta E_{*}\right)$ during $D S$.

The water mass balance applied to the fraction of rainfall intercepted by the canopy, can be tested by checking the balance of the inflowing volumes as interception during the $i$ $W S$ s and the outflowing volumes, as evaporation from the canopy, during the $j D S s$, where of course the antecedent stored volumes $I C S_{0}$ are involved:

$$
\sum_{W S=1}^{i}\left(I C S-I C S_{0}\right)=\sum_{D S=1}^{j} \Delta E_{*}
$$

Once evaporation losses are calculated, the net rainfall $R_{n}(\mathrm{~mm})$ can be evaluated:

$$
R_{n}=R-\sum_{D S=1}^{j} \Delta E_{*}
$$

\section{Interception Capacity LAI and Evaporation Measurements for Faba Bean}

In order to show the results that can be obtained by the application of the simplified procedure, the 2019 rainfall (Figure 2) and temperature data series of Fontanasalsa station were considered, and the required empirical parameters of Equation (19) were obtained by experimental measurements carried out for faba bean. Faba bean is a species of flowering plant in the pea and bean family Fabaceae, originated in the continent of Africa, which is widely cultivated as a crop for human consumption and also used as a cover crop. 
For a single plant, planted in mid-November, and sampled after 95 days, the temporal variation of water loss by evaporation starting from the interception capacity, the number of leaves, \# Leaves, and the corresponding surface area were measured. Saturation of the canopy was achieved by using sprinkler irrigation, for a fixed outdoor temperature, $T_{e x}=12^{\circ} \mathrm{C}$.

Starting from the interception capacity condition, after dripping has ceased, water loss by evaporation was measured by weighing during the time. The \# Leaves (45), and the corresponding surface area $\left(0.043 \mathrm{~m}^{2}\right)$, made it possible to calculate the cumulative evaporation volume, per unit leaf surface area, $E(\mathrm{~mm})$.

Figure 10a plots the cumulate experimental $E$ values during the time. This made it possible to calculate by a simple linear regression of the corresponding logarithmic values, the $m$ and $n$ parameters that are required to apply Equation (16). According to Babu et al. [36], Figure 10a shows that in a first stage evaporation rate is high, and then the evaporation rate decreases remaining almost constant in the time, for approximately $t=1 \mathrm{~h}$ (at least for this case), the behavior of which can be described by the power-law well.
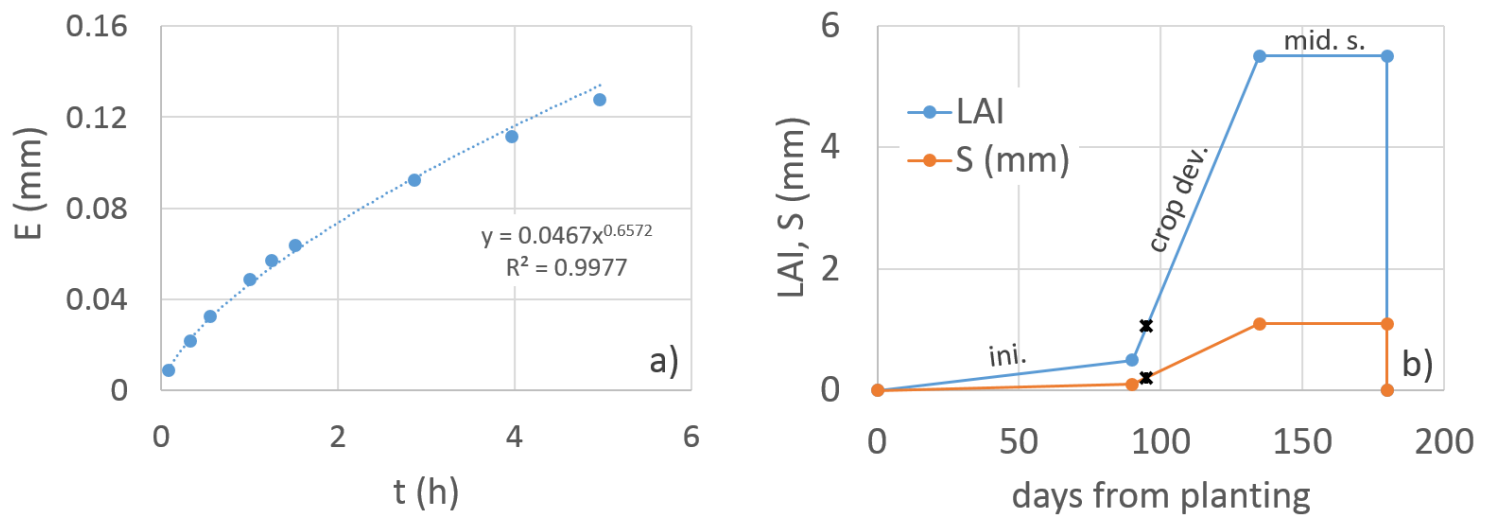

Figure 10. For Field bean, (a) relationship between experimental evaporation losses per unit $L A I, E / L A I$, during the time $t$ (h), starting from the interception capacity, $S(\mathrm{~mm})$, and $(\mathbf{b})$ assumed temporal variation of $L A I$ and $S$ ( $\mathrm{mm}$ ), from the day of planting (mid-November), considered for the application (Figure 11).

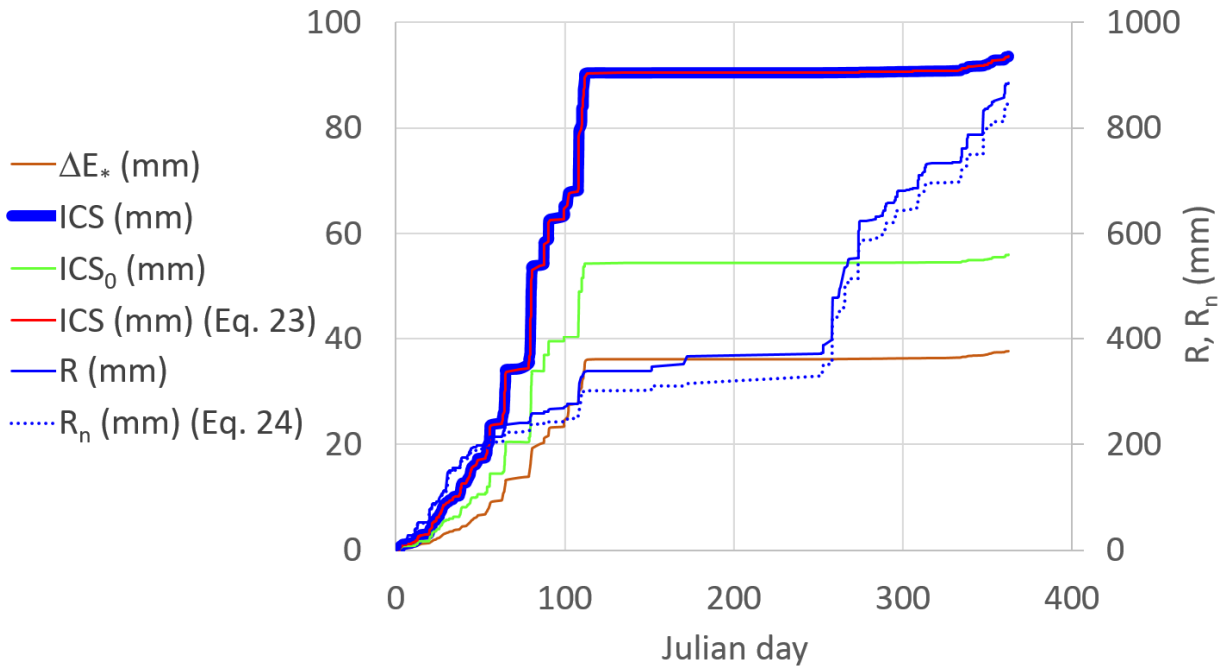

Figure 11. For the year 2009, evaporation loss $\Delta E_{*}$, interception loss, ICS, antecedent volume stored on the canopy, ICS $S_{0}$ The figure also illustrate the water mass balance (red line) that was checked by using Equation (23), and the gross and net rainfall depth, $R$ and $R_{n}$ (Equation (24)), respectively (secondary axis).

Of course, it should be noted that there are other secondary factors not considered in the present approach, such as the plant structure, the leaf angle and the light interception, 
although not easy to consider, which may affect the considered parameters [43], especially when upscaling is needed.

For the purpose of the present investigation, the relationship between the interception capacity and $L A I$ was considered in order to extend to 2009 , the corresponding relationships displayed in Figure 10a, which are related to the limited experimental $L A I$ value. To consider the $L A I$ temporal variations, some data for faba bean available in the literature were considered.

For faba bean planted in mid-November, as in this study, in El-Bosaily farm in the Northern coast of Egypt, Hegab et al. [44] measured a maximum LAI value equal to 5.5. This value was assumed for the mid-season stage according to FAO56 [35], which provides general lengths for four distinct growth stages, initial (ini.), crop development (crop dev.), mid-season (mid. s.) and late season (late), for various, crops, types of climates and locations.

For faba bean, FAO56 [35] reports ini. $=90$, crop dev. $=45$, mid.s. $=40$, late $\mathrm{s} .=0$ days, thus no late season was considered since it was assumed that after the mid-season the faba bean was fully removed from the field. For the four growth stages, Figure 10b shows the $L A I$ variations versus the days from planting that made it possible the applications described in the next section to be performed. In Figure 10b can be observed that it was assumed that the crop development stage, after 90 days from planting, starts with $L A I=0.5$.

According to Brisson et al. [45], the interception capacity was assumed $S=0.2$ LAI. Thus, with increasing $L A I$ during crop growth and decreasing $L A I$ during senescence, $S$ will increase and decrease, respectively. More recently, this relationship between $S$ and $L A I$ was also considered by Kozak et al. [46]. Figure 10b also graphs the $S$ variation during the days from planting. The interception capacity in the day of sampling (cross symbol), i.e., after 95 days from the day of planting, was equal to 0.202 , not too far from that experimentally measured (0.156).

It should be noted that other $S$ vs. LAI relationships could be used in the presented methodology, and that specific methods, as that proposed by Aston [47] who also found a linear $S$ vs. $L A I$ relation, could be applied in order to experimentally determine such relationships that depend on the considered crops.

\section{Example of Application}

For the considered crop described in the previous section (Figure 10a,b), for $C_{F}=1$ and $p=0$, and for the 2019 rainfall data series, interception and evaporation losses were calculated according to the described procedure. Figure 11 plots the detailed results of the involved cumulative water balance components, i.e., the rainfall depth, $R(\mathrm{~mm})$, the interception depth at the end of each wet spell, ICS, and the evaporation losses, $\Delta E_{*}$. The latter made it possible to evaluate the antecedent stored volume before each $W S, I C S_{0}=I C S-\Delta E_{*}$.

The figure also illustrate the volume water mass balance (red line) that was checked by using Equation (23). Of course, the interception process mostly occurs during the growing season when it rains. For the considered year, 2009, the evaporation loss by canopy achieved $37.6 \mathrm{~mm}$. Figure 11 also plots the net rainfall (dashed line), calculated according to Equation (24).

It is interesting to observe that the rainiest periods (1-110 and 250-365 Julian day) are not associated with the periods with the highest evaporation losses (1-110 Julian day). Of course, this is explained by the rainfall distribution, which has to be analyzed with respect to the growing period of the considered crop, playing a fundamental role in detecting evaporation losses by the rainfall intercepted by the canopy. Evaporation losses for the considered cover crop are $4.5 \%$ with respect to the yearly rainfall, and are thus lower than the minimum found in other studies [28], despite different cover crops being considered, whereas interception losses are of course higher and equal to $10.58 \%$.

However, this author is of the opinion that comparison of these values with those obtained in other studies is not very meaningful, due to the high interactions between climate variability, rainfall distribution, and cover crop management (growing season, date 
of planting, etc.) that should be analyzed to explain the impact of inter-annual variability of interception/evaporation losses [48]. In this sense, the procedure described in this work could be useful to study in deep these interactions, also accounting for the other parameters as the cover fraction, the date of planting [42], the throughfall index and different rainfall regimes and their changes $[33,49]$ that were not considered in this work.

\section{Conclusions}

In order to derive the evaporation losses by wet canopy, the suggested procedure combines a modified interception model proposed by Merrian, which is applied during rainfall wet spells, and a simple power-law equation to model evaporation during the dry spells. This simple approach makes it possible to estimate the evaporation losses during continuous simulations, and requires few parameters that consolidate climate and crop conditions. Moreover, it is shown that the Merrian model can be derived by considering a simple linear storage model that makes it possible to account of the antecedent intercepted volume, which is useful for applications. The crop considered in the application is the faba bean that was described according to the general lengths of four distinct growth stages considered in FAO56, whereas LAI and interception capacity were obtained from literature. Since the required parameters are few, this simple approach could be applied when a rough estimate of evaporation loss by wet canopy is necessary, in the absence of a detailed characterization of canopy and climate. Due to simplified schemes, the procedure can be easily applied at large scale, in order to study the important role of rainfall regime and crop growing stages, on this important component of the hydrologic cycle, and it could be suitable to be implemented according to a probabilistic line of approach.

Funding: This research received no external funding.

Data Availability Statement: All data, models, and code, generated or used during the study appear in the published article.

Acknowledgments: The author wish to thank Agata Novara for providing evaporation measurements, and the three anonymous reviewers for the helpful comments and suggestions during the revision stage.

Conflicts of Interest: The author declares no conflict of interest.

\section{References}

1. Brutsaert, W. Hydrology: An Introduction, 5th ed.; Cambridge University Press: Cambridge, UK, 2010.

2. Zhang, Y.; Li, X.Y.; Li, W.; Wu, X.C.; Shi, F.Z.; Fang, W.W.; Pei, T.T. Modeling rainfall interception loss by two xerophytic shrubs in the Loess Plateau. Hydrol. Process. 2017, 31, 1926-1937. [CrossRef]

3. Dunkerley, D. Measuring interception loss and canopy storage in dryland vegetation: A brief review and evaluation of available research strategies. Hydrol. Process. 2000, 14, 669-678. [CrossRef]

4. Savenije, H.H.G. The importance of interception and why we should delete the term evapotranspiration from our vocabulary. Hydrol. Process. 2004, 18, 1507-1511. [CrossRef]

5. Zhang, Y.F.; Wang, X.P.; Hu, R.; Pan, Y.X. Throughfall and its spatial variability beneath xerophytic shrub canopies within water-limited arid desert ecosystems. J. Hydrol. 2016, 539, 406-416. [CrossRef]

6. Baiamonte, G.; Singh, V.P. Overland Flow Times of Concentration for Hillslopes of Complex Topography. J. Irrig. Drain. E-ASCE 2016, 142, 04015059. [CrossRef]

7. Baiamonte, G. Simplified model to predict runoff generation time for well-drained and vegetated soils. J. Irrig. Drain. E-ASCE 2016, 142, 04016047. [CrossRef]

8. Cullotta, S.; Bagarello, V.; Baiamonte, G.; Gugliuzza, G.; Iovino, M.; La Mela Veca, D.S.; Maetzke, F.; Palmeri, V.; Sferlazza, S. Comparing different methods to determine soil physical quality in a Mediterranean forest and pasture land. Soil Sci. Soc. Am. J. 2016, 80, 1038-1056. [CrossRef]

9. Bagarello, V.; Baiamonte, G.; Caia, C. Variability of near-surface saturated hydraulic conductivity for the clay soils of a small Sicilian basin. Geoderma 2019, 340, 133-145. [CrossRef]

10. Baiamonte, G.; Bagarello, V.; D’Asaro, F.; Palmeri, V. Factors influencing point measurement of near-surface saturated soil hydraulic conductivity in a small Sicilian basin. Land Degrad. Dev. 2017, 28, 970-982. [CrossRef]

11. Gash, J.H.C.; Wright, I.R.; Lloyd, C.R. Comparative estimates of interception loss from three coniferous forests in Great Britain. J. Hydrol. 1980, 48, 89-105. [CrossRef] 
12. Ubarana, V.N. Observations and Modelling of Rainfall Interception at Two Experimental Sites in Amazonia. In Amazonian Deforestation and Climate; Gash, J.H.C., Nobre, C.A., Roberts, J.M., Victoria, R.L., Eds.; John Wiley \& Sons: Hoboken, NJ, USA, 1996; 611p.

13. Calder, I. Evaporation in the Uplands; Wiley: Chichester, UK; New York, NY, USA, 1990.

14. Muzylo, A.; Llorens, P.; Valente, F.; Keizer, J.J.; Domingo, F.; Gash, J.H.C. A review of rainfall interception modelling. J. Hydrol. 2009, 370, 191-206. [CrossRef]

15. Linsley, R.K., Jr.; Kohler, M.A.; Paulhus, J.L. Applied Hydrology; McGraw-Hill Book Co.: New York, NY, USA, 1988.

16. Horton, R.E. Rainfall interception. Mon. Weather Rev. 1919, 47, 603-623. [CrossRef]

17. Merriam, R.A. A note on the interception loss equation. J. Geophys. Res. 1960, 5, 3850-3851. [CrossRef]

18. Merriam, R.A. Fog drip from artificial leaves in a fog wind tunnel. Water Resour. Res. 1973, 9, 1591-1598. [CrossRef]

19. Rutter, A.J.; Kershaw, K.A.; Robins, P.C.; Morton, A.J. A predictive model of rainfall interception in forests, 1 . Derivation of the model from observations in a plantation of Corsican pine. Agric. Meteorol. 1971, 9, 367-384. [CrossRef]

20. Rutter, A.J.; Morton, A.J.; Robins, P.C. A predictive model of rainfall interception in forests. II. Generalization of the model and comparison with observations in some coniferous and hardwood stands. J. Appl. Ecol. 1975, 12, 367-380. [CrossRef]

21. Calder, I. A model of transpiration and interception loss from a spruce forest in Plynlimon, Central Wales. J. Hydrol. 1977, 33, 247-265. [CrossRef]

22. Gash, J.; Morton, A. Application of the Rutter model to the estimation of the interception loss from Thetford forest. J. Hydrol. 1978, 38, 49-58. [CrossRef]

23. Monteith, J.L. Evaporation and environment. Syrup. Soc. Exp. Biol. 1965, 19, 205-234.

24. Gash, J.H.C. An analytical model of rainfall interception by forests. Q. J. R. Meteorol. Soc. 1979, 105, 43-55. [CrossRef]

25. Pearce, A.J.; Rowe, L.K.; Stewart, J.B. Nightime, wet canopy evaporation rates and the water balance of an evergreen mixed forest. Water Resour. Res. 1980, 16, 955-959. [CrossRef]

26. Dolman, A.J. Summer and winter rainfall interception in an oak forest. Predictions with an analytical and a numerical simulation model. J. Hydrol. 1987, 90, 1-9. [CrossRef]

27. Lloyd, C.R.; Gash, J.H.C.; Shuttleworth, W.J.; Marques, A.O. The measurement and modelling of rainfall interception by amazonian rain forest. Agric. For. Meteorol. 1988, 43, 277-294. [CrossRef]

28. Coutuntrn, D.E.; Ripley, E.A. Rainfall interception in mixed grass prairie. Can. J. Plant Sci. 1973, 53, 659-663.

29. Von Hoyningen-Hüne, J. Die Interception des Niederschlags in landwirtschaftlichen Beständen. Schr. Des. DVWK 1983, 57, 1-53.

30. Braden, H. Ein Energiehaushalts- und Verdunstungsmodell for Wasser und Stoffhaushaltsuntersuchungen landwirtschaftlich genutzer Einzugsgebiete. Mittelungen Dtsch. Bodenkd. Geselschaft 1985, 42, 294-299.

31. van Dam, J.C.; Huygen, J.; Wesseling, J.G.; Feddes, R.A.; Kabat, P.; van Walsum, P.E.V.; Groenendijk, P.; van Diepen, C.A. Theory of SWAP Version 2.0. Simulation of Water Flow, Solute Transport and Plant Growth in the Soil-Water-Atmosphere-Plant Environment; Technical Document 45; Wageningen Agricultural University; DLOW Winand Staring Centre: Wageningen, The Netherlands, 1997.

32. Agnese, C.; Baiamonte, G.; Cammalleri, C. Modelling the occurrence of rainy days under a typical Mediterranean climate. Adv. Water Res. 2014, 64, 62-76. [CrossRef]

33. Baiamonte, G.; Mercalli, L.; Cat Berro, D.; Agnese, C.; Ferraris, S. Modelling the frequency distribution of interarrival times from daily precipitation time-series in North-West Italy. Hydrol. Res. 2019, 50, 339-357. [CrossRef]

34. Baiamonte, G.; Agnese, C. Quick and Slow Components of the Hydrologic Response at the Hillslope Scale. J. Irrig. Drain. E-ASCE 2016, 142, 04016038. [CrossRef]

35. Allen, R.G.; Pereira, L.S.; Raes, D.; Smith, M. Crop Evapotranspiration. Guidelines for Computing Crop Water Requirements; FAO Irrigation and Drainage Paper 56; FAO: Rome, Italy, 1998; 300p.

36. Babu, A.K.; Kumaresan, G.; Raj, V.A.A.; Velraj, R. Review of leaf drying: Mechanism and influencing parameters, drying methods, nutrient preservation, and mathematical models. Renew. Sustain. Energy Rev. 2018, 90, 536-556. [CrossRef]

37. Black, T.A.; Gardner, W.R.; Thurtell, G.W. The prediction of evaporation, drainage, and soil water storage for a bare soil. Soil Sci. Soc. Am. Proc. 1969, 33, 655-660. [CrossRef]

38. Ritchie, J.T. Model for predicting evaporation from a row crop with incomplete cover. Water Resour. Res. 1972, 8, 1204-1213. [CrossRef]

39. Pumo, D. L'Approvvigionamento Idrico per l'Agricoltura; Aracne Editrice SRL: Rome, Italy, 2008; ISBN 978-88-548-1708-1. (In Italian).

40. Pereira, L.S.; Paredes, P.; Melton, F.; Johnson, L.; Wang, T.; López-Urrea, R.; Cancela, J.J.; Allen, R.G. Prediction of crop coefficients from fraction of ground cover and height. Background and validation using ground and remote sensing data. Agric. Water Manag. 2020, 241, 106197. [CrossRef]

41. Lee, K.J.; Lee, B.W. Estimating canopy cover from color digital camera image of rice field. J. Crop Sci. Biotechnol. 2011, 14, 151-155. [CrossRef]

42. Fernandez-Gallego, J.A.; Kefauver, S.C.; Kerfal, S.; Araus, J.L. Comparative canopy cover estimation using RGB images from UAV and ground. In Proceedings of the Remote Sensing for Agriculture, Ecosystems, and Hydrology XX, Berlin, Germany, 10-13 September 2018; p. 107830J. [CrossRef]

43. Knapp, A.K.; Smith, D.L. Leaf Angle, Light Interceptoon \& Water Relations, Demonstrating How Plants Cope with Multiple Resource Limitations in the Field. Am. Biol. Teach. 1997, 59, 365-368. 
44. Hegab, A.S.A.; Fayed, M.T.B.; Hamada, M.M.A.; Abdrabbo, M.A.A. Productivity and irrigation requirements of faba-bean in North Delta of Egypt in relation to planting dates. Ann. Agric. Sci. 2014, 59, 185-193. [CrossRef]

45. Brisson, N.; Mary, B.; Riposche, D.; Jeuffroy, M.; Ruget, F.; Gate, P.; Devienne-Barret, F.; Antonioletti, R.; Durr, C.; Nicoullaud, B.; et al. STICS: A generic model for the simulation of crops and their water and nitrogen balance. I. Theory and parameterization applied to wheat and corn. Agronomie 1998, 18, 311-316. [CrossRef]

46. Kozak, J.A.; Ahuja, L.R.; Green, T.R.; Ma, L. Modelling crop canopy and residue rainfall interception effects on soil hydrological components for semi-arid agriculture. Hydrol. Process. 2007, 21, 229-241. [CrossRef]

47. Aston, A.R. Rainfall interception by eight small trees. J. Hydrol. 1979, 42, 383-396. [CrossRef]

48. Meyer, N.; Bergez, J.E.; Constantin, J.; Belleville, P.; Justes, E. Cover crops reduce drainage but not always soil water content due to interactions between rainfall distribution and management. Agric. Water Manag. 2020, 231, 105998. [CrossRef]

49. Tripathi, S.; Govindaraju, R.S. Change detection in rainfall and temperature patterns over India. In Proceedings of the Third International Workshop on Knowledge Discovery from Sensor Data (SensorKDD 2009), Paris, France, 28 June 2009; Association for Computing Machinery: New York, NY, USA, 2009; pp. 133-141. [CrossRef] 